\title{
Research on the Vibration Characteristics of a Compounded Periodic Strut Used for Helicopter Cabin Noise Reduction
}

\author{
Yang Lu, Fengjiao Wang, and Xunjun Ma \\ National Key Laboratory of Rotorcraft Aeromechanics, Nanjing University of Aeronautics and Astronautics, Nanjing 210016, China \\ Correspondence should be addressed to Yang Lu; njluyang@163.com
}

Received 21 May 2017; Accepted 8 August 2017; Published 3 October 2017

Academic Editor: Matteo Filippi

Copyright (c) 2017 Yang Lu et al. This is an open access article distributed under the Creative Commons Attribution License, which permits unrestricted use, distribution, and reproduction in any medium, provided the original work is properly cited.

\begin{abstract}
A special periodic strut is developed to reduce the helicopter cabin noise in this paper. The strut exhibits unique dynamic characteristics which can isolate the gearbox vibrations from transferring to the fuselage and radiating noise. Modeling, simulation, and experimental research are carried out to explore its characteristics and performance. A theoretical model of the strut is firstly established, with particular emphasis on correlating the passband and stop band behaviors with the damping and a series of boundary conditions. Then, through simulations, it is shown that both the damping and boundary conditions have significant influences on the stop band, including the beginning and end frequencies and attenuation effects. Based on these analytical simulations, experimental analyses are conducted with the newly developed strut. Inspiring performances are validated under different conditions. Considering that the helicopter vibration in practical applications is much more complex, further experimental investigations are carried out on a helicopter model, which generates prominent gear mesh tones similar to a real helicopter. The experimental results show that the compounded periodic strut can significantly attenuate the vibrations transmitted to the fuselage. Compared with the plain strut, attenuations in excess of $40 \mathrm{~dB}$ are measured in the frequency range from $300 \mathrm{to} 2000 \mathrm{~Hz}$.
\end{abstract}

\section{Introduction}

Noise in a helicopter cabin is usually an annoyance for both passengers and pilots. From the perspective of frequency analysis, mid-frequency and high-frequency harmonic vibrations generated by meshing gear pairs are a significant source of helicopter cabin noise because they can have a great influence on the subjective reaction of a human [1-3]. The typical frequency range is between $500 \mathrm{~Hz}$ and $2000 \mathrm{~Hz}$ [1]. Part of gear mesh excitation vibration is transmitted through the air into the helicopter cabin as sound, and the other part is transmitted through the support structure between the main gearbox and the fuselage, thereby entering into the airframe and finally radiating structure-borne sound into the cabin [4]. Comprehensive analysis has shown that the latter path is dominant [5]; thus, the cabin noise can be controlled by suppressing the vibration transferred to the fuselage. Currently, two main methods are used to address this problem.
One method is to actively isolate the gear mesh vibration using actuators installed on the supported struts or nearby the mount points of the struts as secondary forces. In 1997, the Institute of Sound and the Vibration Research at the University of Southampton cooperating with Westland Helicopters investigated experimentally an EH101 support strut under realistic loading conditions [6]. Three magnetostrictive actuators were clamped to the strut to introduce secondary forces that finally realized attenuation in the range of $30-40 \mathrm{~dB}$ in the kinetic energy of vibration over the frequency range of $250-1250 \mathrm{~Hz}$. In addition, Eurocopter Deutschland and the EADS Corporate Research Center introduced smart struts to control the structure-borne sound transmitted via the struts to the fuselage $[7,8]$. The smart strut consists of piezoelectric actuators that are directly bonded to the BK117 support struts and provides good effectiveness at controlling the noise of multiple gear mesh frequencies in a flight test. In addition, the Sikorsky Aircraft Corporation and the Boeing Company each utilized different point force actuators mounted near the 
support struts $[3,9]$. The active noise control (ANC) system uses cabin noise as feedback and produces a high capability to reduce the primary gear mesh tone over a wide range of steady and transient flight conditions. Lu and $\mathrm{Ma}$ in Nanjing University of Aeronautics and Astronautics presented an active structural acoustic control (ASAC) system to reduce the noise of multiple gear mesh frequencies [10]. The researches on the helicopter gearbox/fuselage model showed that the algorithm can effectively control noise of multiple gearbox harmonic frequencies in a cabin.

In the present study, active methods can manage multiple gear mesh frequency components effectively; however, its broadband reduction ability is very limited. In addition, several inherent problems are presented, such as actuator/sensor location optimization, stability of active control algorithms, and high cost $[11,12]$.

An alternative is to embed in the gearbox strut with a metal/rubber periodic structure, that is, a type of structure with geometrical discontinuity or material discontinuity. Periodic structures have unique dynamic characteristics of restricting wave propagation within specific frequency bands, called "stop bands." With proper design, the periodic strut can realize broadband vibration attenuation from the gearbox to the fuselage. A considerable number of studies have been performed by the University of Maryland and Pennsylvania State University. At the University of Maryland, Asiri et al. developed a new class of gearbox periodic struts containing five metal and elastomer cells for helicopter cabin noise reduction [13]. The broadband attenuation effect of the periodic strut has been preliminarily verified experimentally with a principle model of the gearbox system. At Pennsylvania State University, Szefi et al. presented a helicopter gearbox isolator using elastomer layers for gearbox vibration isolation $[2,14-17]$. The research results showed that the range of stop bands can be designed by parameter optimization.

Although good vibration attenuation effects of periodic struts and periodically layered isolators have been presented, the feasibility of engineering application is not considered; thus, the structures cannot function properly under realistic rotor pull-pull loading conditions. To solve this problem, in Wang and Lu's group, a series/parallel compounded gearbox periodic strut for helicopter cabin noise reduction was proposed with modeling, parameter analysis, and simulation verified studies [18]. Note that the influence of damping and boundary conditions were not considered in [18]. Later, research found that the impact of these factors on the design of compounded periodic strut should not be neglected. The vibration characteristics of the strut also require further experimental investigations. Based on the above reasons, this paper presents poststudy on the compounded gearbox periodic strut with simulations and experiments.

This paper is organized into six sections. Section 1 gives a brief introduction. In Section 2, with the damping and boundary conditions introduced, a more complete dynamic model of the compounded periodic strut is presented. Section 3 analyzes the influence of the parameters. A compounded periodic strut is developed for a certain helicopter model in Section 4. Section 5 demonstrates the broadband vibration attenuation characteristics of the strut and evaluates

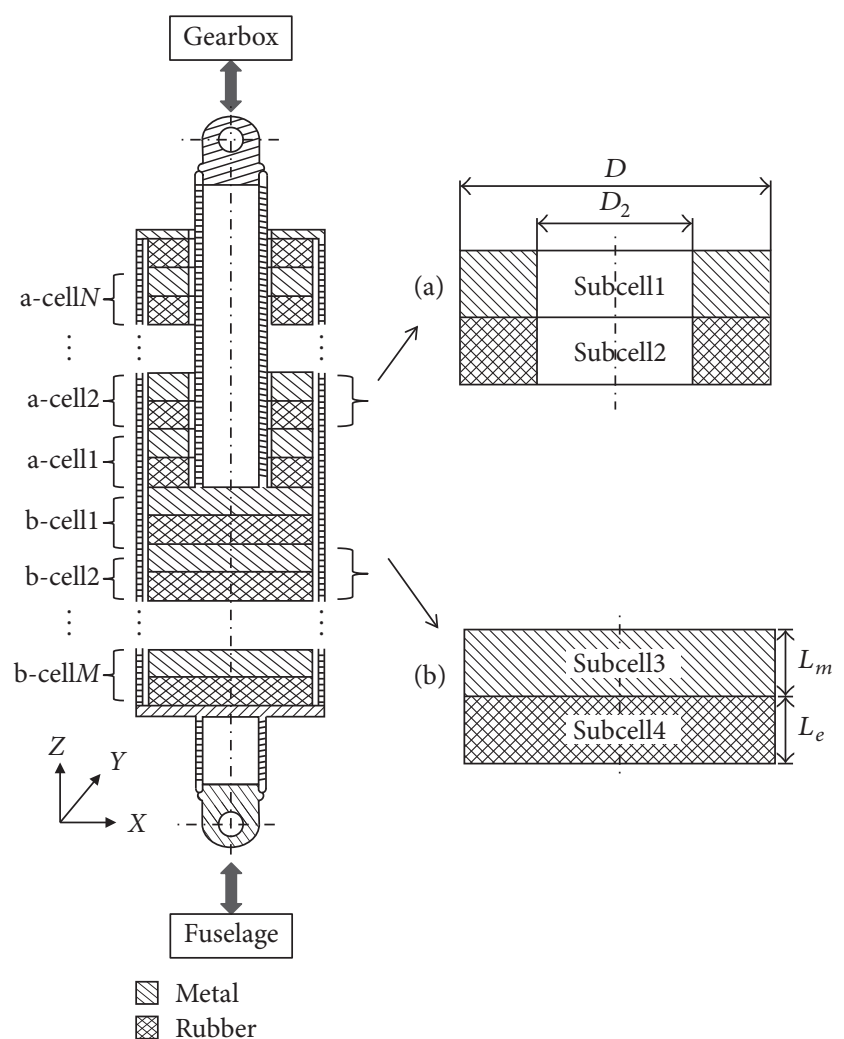

FIGURE 1: Schematic illustration of a compounded periodic strut for a gearbox.

the effect of precompression. In this section, two experimental systems are presented, including a shaker broadband excitation system and a gearbox excitation system. Section 6 summarizes the conclusions of the present study.

\section{Dynamics Modeling}

2.1. Overview. Figure 1 shows the schematic drawing of the compounded periodic strut [18]. The strut can be divided into three parts: joints, a cylindrical shell, and a compounded periodic structure that is embedded inner cylindrical shell. The compounded periodic structure is mainly composed of two types of cells, called a-cells and b-cells, with series-parallel connections along the $z$-axis. For illustrative convenience, the periodic structure composed of $N$ a-cells in series is defined as the upper cylinder, the periodic structure composed of $M$ b-cells in series is defined as the lower cylinder, the upper and lower cylinders in series compose the inner cylinder, and the outer cylindrical shell is defined as the outer cylinder.

Based on the Spectral Finite Element (SFE) method, the strut can be divided into various subcells with different geometric dimensions or material parameters. For illustration, the subcells in Figures 1(a) and 1(b) numbered 1, 2, 3, and 4 are used to form a-cells and b-cells. In the case of the stiffness characteristic, the joints can be neglected. Each remainder subcell can be approximately regarded as a one-dimensional rod. 
In this section, the emphasis is placed on studying the dynamics of the compounded periodic strut alone. The dynamic model of subcells is established first using the complex damping assumption and the SFE method, and then the dynamic model of the entire periodic strut is established these subcells. The different boundary conditions are given to determine the transfer relationship of the strut in detail.

2.2. Dynamics of the Subcell. Based on the SFE method, the dynamic stiffness matrix of a subcell can be described as follows [13]:

$$
\mathbf{K}_{\text {sub }}=\frac{E A}{l} \frac{i k l}{\left(1-e^{-2 i k l}\right)}\left[\begin{array}{cc}
1+e^{-2 i k l} & -2 e^{-i k l} \\
-2 e^{-i k l} & 1+e^{-2 i k l}
\end{array}\right],
$$
related to vibration frequency $\omega . E$ and $\rho$ are the elastic modulus and mass density of the material, respectively. In addition, $A$ and $l$ are the cross-sectional area and longitudinal length of the subcell, respectively. Subscript sub defines the parameters of a subcell.

As rubber is a viscoelastic material, part of the vibration energy dissipates in the form of heat energy under the considering the series-parallel connection relationship of

where $k=\omega \sqrt{\rho A /(E A)}$ is the longitudinal wavenumber,

excitation. The obvious mechanical behavior is that stress has a phase lag with regard to strain [19]. Thus, the elastic modulus can be expressed as the plural form:

$$
E=E^{\prime}+E^{\prime \prime}=E^{\prime}(1+i \eta),
$$

where $E^{\prime}, E^{\prime \prime}$, and $\eta$ are the storage modulus, loss modulus, and loss factor of material, respectively.

The forces at the ends of the subcell are related to displacements by the following relation:

$$
\left[\begin{array}{l}
F_{\mathrm{U}} \\
F_{\mathrm{L}}
\end{array}\right]=\left[\begin{array}{ll}
K_{\mathrm{UU}} & K_{\mathrm{UL}} \\
K_{\mathrm{LU}} & K_{\mathrm{LL}}
\end{array}\right]\left[\begin{array}{l}
u_{\mathrm{U}} \\
u_{\mathrm{L}}
\end{array}\right],
$$

where $F$ and $u$ define the longitudinal force and longitudinal displacement vectors, respectively, with subscripts $U$ and $\mathrm{L}$ denoting the upper and lower sides, respectively.

2.3. Dynamics of the Entire Periodic Strut. The compounded periodic strut can be regarded as a series-parallel complicated structure consisting of multiple subcells. Based on the former dynamics of the subcell, the damped dynamics of the entire periodic strut can be derived.

The dynamics stiffness matrix of $n$ subcells in series gives

$$
\mathbf{K}_{s}=\left[\begin{array}{ccccc}
K_{1 \mathrm{UU}} & K_{1 \mathrm{UL}} & 0 & \cdots & 0 \\
K_{1 \mathrm{LU}} & K_{1 \mathrm{LL}}+K_{2 \mathrm{UU}} & K_{2 \mathrm{UL}} & \ldots & 0 \\
0 & K_{2 d u} & K_{2 \mathrm{LL}}+K_{3 \mathrm{UU}} & \cdots & \vdots \\
\vdots & \vdots & \vdots & K_{(n-1) \mathrm{LL}}+K_{n \mathrm{UU}} & K_{n \mathrm{UL}} \\
0 & 0 & \cdots & K_{n \mathrm{LU}} & K_{n \mathrm{LL}}
\end{array}\right] .
$$

Moreover, the dynamics stiffness matrix of $n$ subcells in parallel gives

$$
\mathbf{K}_{p}=\mathbf{K}_{1 \text { sub }}+\mathbf{K}_{\text {2sub }}+\cdots+\mathbf{K}_{\text {nsub }} .
$$

As $N$ a-cells and $M$ a-cells in series form the upper and lower cylinder, respectively, the different dimension caused by the stiffness matrix cannot be derived using (4) and (5). Here, a new calculation method of the compounded structure is given.

First, the dynamics of a subcell as determined from (3) can be rearranged to take the following form [13]:

$$
\left[\begin{array}{l}
u_{\mathrm{L}} \\
F_{\mathrm{L}}
\end{array}\right]=\left[\begin{array}{cc}
-K_{\mathrm{UL}}^{-1} K_{\mathrm{UU}} & K_{\mathrm{UL}}^{-1} \\
-K_{\mathrm{LU}}+K_{\mathrm{LL}} K_{\mathrm{UL}}^{-1} K_{\mathrm{UU}} & -K_{\mathrm{LL}} K_{\mathrm{UL}}^{-1}
\end{array}\right]\left[\begin{array}{c}
u_{\mathrm{U}} \\
F_{\mathrm{U}}
\end{array}\right],
$$

where the transfer matrix can be denoted as $\mathbf{T}_{\text {sub }}$ in (6).

The transfer matrix of $n$ subcells in series can be computed as

$$
\mathbf{T}_{s}=\mathbf{T}_{n s u b} \cdots \mathbf{T}_{2 \text { sub }} \mathbf{T}_{1 \text { sub }} .
$$

Using the transformation given in (6), the transfer matrix can be transferred into the dynamics stiffness matrix. The new dynamics stiffness matrix of $n$ subcells in series becomes

$$
\overline{\mathbf{K}}_{s}=\left[\begin{array}{cc}
-\left(T_{12}\right)^{-1} T_{11} & \left(T_{12}\right)^{-1} \\
-T_{21}+T_{22}\left(T_{12}\right)^{-1} T_{11} & -T_{22}\left(T_{12}\right)^{-1}
\end{array}\right]_{a},
$$

where the dimension transforms into $2 \times 2$, which is different from (4). Next, it can be easily adapted to obtain dynamics stiffness matrix of each part of the periodic strut with the same dimension.

Combining (5) and (8), the damped dynamics matrix of the entire periodic strut gives

$$
\left[\begin{array}{l}
F_{\mathrm{U}} \\
F_{\mathrm{L}}
\end{array}\right]=\left[\mathbf{K}_{d}\right]\left[\begin{array}{l}
u_{\mathrm{U}} \\
u_{\mathrm{L}}
\end{array}\right],
$$

where the dynamics matrix can be denoted as $\mathbf{K}_{d}$.

2.4. Transfer Characteristics. Considering the influence of the boundary conditions on the transfer relationship of 
the periodic strut, three classical boundary conditions are introduced. Next, the structural responses and the transfer characteristics can be obtained under harmonic excitation.

Free-Free. The boundary conditions for the strut that is free at both sides and is excited at its upper side by a harmonic longitudinal force can be expressed as follows:

$$
\begin{aligned}
& u_{\mathrm{U}} \neq 0, \\
& F_{\mathrm{U}}=F_{0} ; \\
& u_{\mathrm{L}} \neq 0, \\
& F_{\mathrm{L}}=0,
\end{aligned}
$$

where $F_{0}$ is the amplitude of the force. According to (9), the relationship of the displacement and force at the two ends of the strut can be obtained:

$$
\begin{aligned}
& u_{\mathrm{L}}=\left(-\left[K_{d}\right]_{11}\left[K_{d}\right]_{21}{ }^{-1}\left[K_{d}\right]_{22}+\left[K_{d}\right]_{12}\right)^{-1} F_{0}, \\
& u_{\mathrm{U}}=-\left[K_{d}\right]_{21}{ }^{-1}\left[K_{d}\right]_{22} u_{\mathrm{L}} .
\end{aligned}
$$

Therefore, the transmissibility of the two ends of the strut can be derived as follows:

$$
T_{Z Z}=\left|\frac{u_{\mathrm{L}}}{u_{\mathrm{U}}}\right|=\left|-\left[K_{d}\right]_{22}^{-1}\left[K_{d}\right]_{21}\right| .
$$

Free-Fix. The boundary conditions for the strut fixed at the lower side and excited at its upper free side by a harmonic longitudinal force can be expressed as follows:

$$
\begin{aligned}
& u_{\mathrm{U}} \neq 0, \\
& F_{\mathrm{U}}=F_{0} ; \\
& u_{\mathrm{L}}=0, \\
& F_{\mathrm{L}} \neq 0 .
\end{aligned}
$$

According to (9), the relationship of the displacement and force at the two ends of the strut can be obtained:

$$
\begin{aligned}
& u_{\mathrm{U}}=\left[K_{d}\right]_{11}{ }^{-1} F_{0}, \\
& F_{\mathrm{L}}=-\left[K_{d}\right]_{21}\left[K_{d}\right]_{11}{ }^{-1} F_{0} .
\end{aligned}
$$

Therefore, the transmissibility of the two ends of the strut can be derived as follows:

$$
T_{Z G}=\left|\frac{F_{\mathrm{L}}}{F_{0}}\right|=\left|-\left[K_{d}\right]_{21}\left[K_{d}\right]_{11}^{-1}\right| .
$$

Free-Base. The boundary conditions for the strut freed at the upper side and the base excited at its lower side by a harmonic longitudinal displacement can be expressed as follows:

$$
\begin{aligned}
& u_{\mathrm{U}} \neq 0, \\
& F_{\mathrm{U}}=0 ; \\
& u_{\mathrm{L}}=u_{0}, \\
& F_{\mathrm{L}} \neq 0,
\end{aligned}
$$

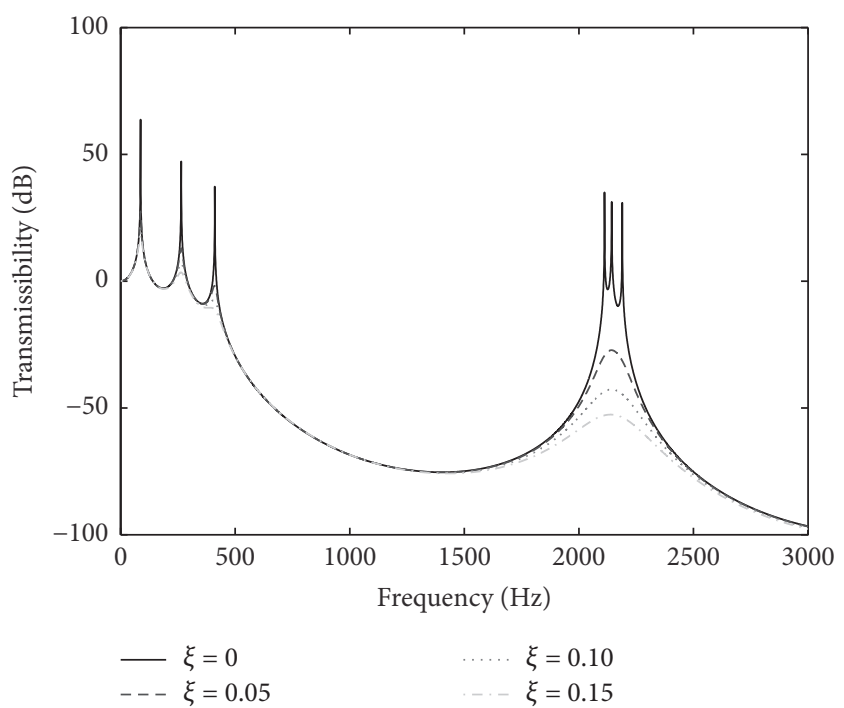

FIGURE 2: Curves of influence of damping on the vibration transmissibility.

where $u_{0}$ is the amplitude of the displacement. According to (9), the relationship of the displacement and force at the two strut ends can be obtained:

$$
\begin{aligned}
& u_{\mathrm{U}}=-\left[K_{d}\right]_{11}^{-1}\left[K_{d}\right]_{12} u_{0}, \\
& F_{\mathrm{L}}=\left(-\left[K_{d}\right]_{21}\left[K_{d}\right]_{11}^{-1}\left[K_{d}\right]_{12}+\left[K_{d}\right]_{22}\right) u_{0} .
\end{aligned}
$$

Hence, the transmissibility of the two ends of the strut can be derived as follows:

$$
T_{Z B}=\left|\frac{u_{\mathrm{U}}}{u_{0}}\right|=\left|-\left[K_{d}\right]_{11}^{-1}\left[K_{d}\right]_{12}\right| .
$$

Clearly, the dynamic stiffness matrix is a symmetric matrix; thus, (15) and (18) have the same result. Hence, the structure transmissibilities of the free-fix and the free-base boundary conditions are equal. Comparing (12) with (15), the structure transmissibilities of the free-free and free-fix boundary conditions are unequal. Thus, it is necessary to provide further analysis of the influence of the boundary conditions.

\section{Parameter Effect Analysis}

3.1. Overview. Numerical analysis of damping and boundary conditions are presented here to demonstrate the importance of providing the compounded periodic strut with proper parameters.

3.2. Damping Effect. Figure 2 shows the transmissibilities for different compounded periodic struts with changing loss factors of rubber. The damping loss factors of natural rubber are in the range from 0.05 to 0.15 . The other material parameters and geometry are the same as [18]. Figure 2 indicates clearly that damping can effectively inhibit the response amplitudes of the resonant frequencies of the compounded periodic 
TABLE 1: Material characteristics.

\begin{tabular}{|c|c|c|c|c|c|}
\hline Material & $\begin{array}{c}\text { Elastic modulus } \\
(\mathrm{GPa})\end{array}$ & $\begin{array}{l}\text { Density } \\
\left(\mathrm{kg} / \mathrm{m}^{3}\right)\end{array}$ & Poisson's ratio & Loss factor & $\begin{array}{c}\text { Allowable stress } \\
(\mathrm{MPa})\end{array}$ \\
\hline Nitrile rubber & 0.005 & 1000 & 0.49 & 0.3 & 3 \\
\hline $45 \#$ steel & 210 & 7860 & 0.3 & 1 & 355 \\
\hline
\end{tabular}

strut. Furthermore, the degree of inhibition is more obvious with the increase in damping and frequency. Therefore, the amplitudes of the resonant frequencies in the range of $2000-2500 \mathrm{~Hz}$ are largely attenuated when considering the effect of damping. Consequently, the stop band range of the periodic strut is effectively broadened.

3.3. Boundary Condition Effect. The stop bands of a onedimensional periodic structure can usually be determined using the classical transfer matrix method. The method, however, neglects the effect of the boundary conditions. Therefore, it is very necessary to analyze its effect on the periodic strut, a finite one-dimensional periodic structure. In this section, the influence of the boundary conditions to the beginning frequencies is mainly analyzed, as the stop band range is the important design objective of the compounded periodic strut and its unapparent end frequencies with damping.

The main influence factors of the vibration attenuation characteristics of the compounded periodic strut include material parameters, geometric dimensions, the number of cells, and damping. By analysis, the factors that largely influence the beginning frequencies are the elastic modulus of rubber, density of metal, rubber/metal's length and length ratio, and diameter of the inner cylinder [18].

Figure 3 displays the changing curves of the differences of the first beginning frequency with the variation of the parameters. The difference is computed by the first beginning frequency of free-fix boundary conditions minus the frequency of free-free boundary conditions. It is clear from the figures that the difference increases with increases in the rubber's elastic modulus and rubber/metal's length ratio. However, as the metal's density, rubber and metal's length increases, and the difference narrows. It can also be noticed that the frequency difference increases first and then decreases with an increase of the inner cylinder's diameter, reaching the largest value at 0.75 .

The comparison shown in Figure 3 suggests that the influence of boundary conditions is significant for a finite periodic strut; the difference of the first beginning frequency can exceed $100 \mathrm{~Hz}$, which should not be ignored in the design of the strut. Whereas the influence of boundary conditions is weakened when the periodic strut approaches an infinite periodic structure.

\section{Sample Strut Development}

4.1. Overview. The goal of this section is to develop a sample of the compounded periodic strut that significantly reduces the gearbox vibration transmitted to an existing helicopter model.
4.2. Design Requirements. Based on the working characteristics of the strut on the helicopter model, the primary requirements pursued to reach this goal were as follows:

(1) Vibration attenuation requirements: the stop band ranges from 300 to $2000 \mathrm{~Hz}$. The targeted tones mainly occur at $360 \mathrm{~Hz}$ and $900 \mathrm{~Hz}$.

(2) Support stiffness requirements: the axial stiffness of a strut is required to be $0.6 \mathrm{MN} / \mathrm{m}$, which can ensure the proper alignment of the engine-transmission shafts and drive shaft.

(3) Intensity requirements: the stress under realistic loading conditions is less than the allowable stress of the material. The compressive deformation of rubber is less than the maximum permissible deformation.

(4) Space requirements: the total length is less than $240 \mathrm{~mm}$, and the diameter is less than $130 \mathrm{~mm}$.

\subsection{Design Parameters}

4.3.1. Materials. The entire periodic strut consists of two materials, as shown in Figure 1. One material is 45\# steel, and the other material is nitrile rubber, which has excellent oil-resistance and heat-resistance properties, a high damping characteristic, and good adhesion to metal. The physical properties of these materials are given in Table 1.

The maximum permissible compressive deformation ratio of nitrile rubber at the static state is $15 \%$.

4.3.2. Geometric Properties. Based on the design process of the compounded periodic strut [18], a group of dimension parameters that meet the design requirements is obtained. The main geometric properties of the upper and lower cylinders are given in Table 2. In addition, the numbers of cells are $N=1$ and $M=2$.

4.3.3. Precompression Deformation. The total compression deformation of rubber is $5 \mathrm{~mm}$, which enables rubber to remain at the state of compression under both tensile and compressive loading conditions.

4.4. Simulation Analysis. Based on the dynamics model of the entire periodic strut in Section 2, the analytical transmissibility for the sample strut under free-fix boundary conditions is presented in Figure 4. The figures clearly indicate that the stop bands include the frequency ranging from 300 to $2000 \mathrm{~Hz}$, and the maximum reduction from one side to the other side of the strut exceeds $50 \mathrm{~dB}$, thereby satisfying the requirement of vibration attenuation. Based on the simulation results, the 


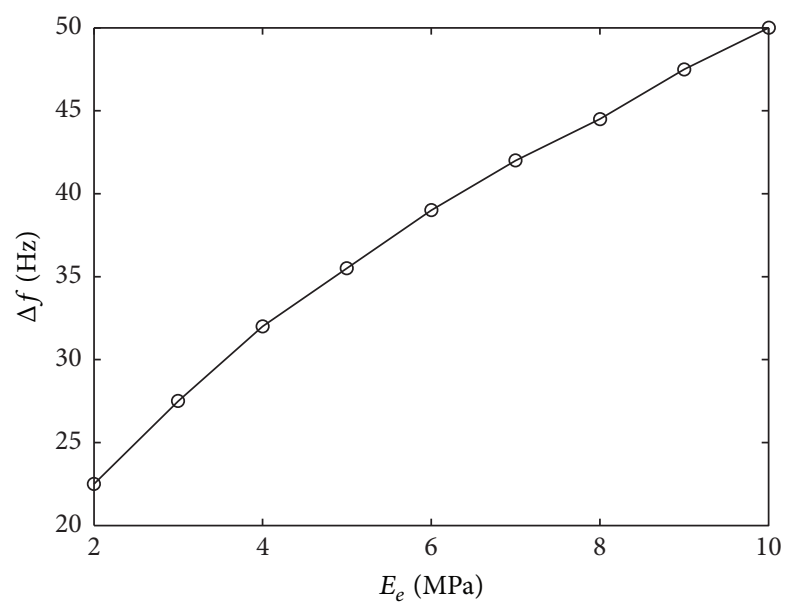

(a) Rubber's elastic modulus

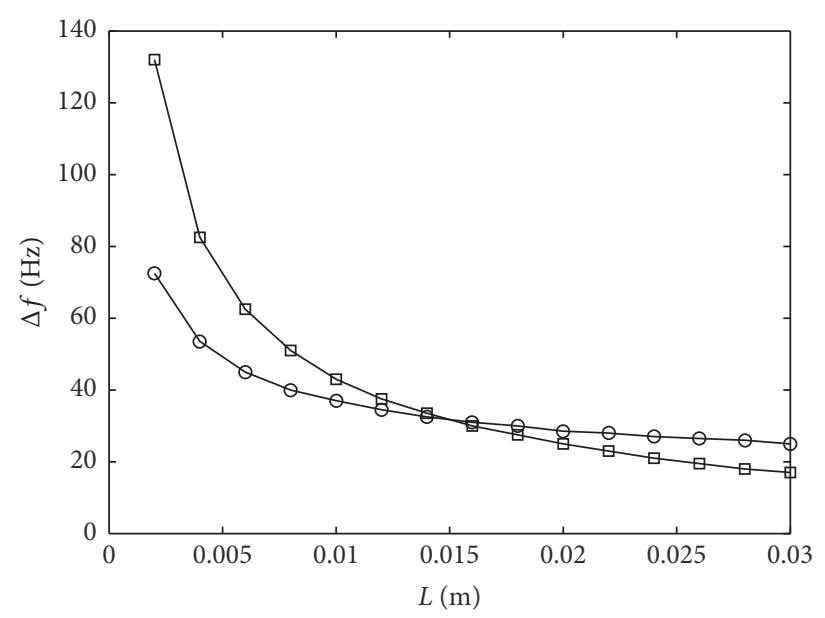

- Rubber

$\rightarrow$ Metal

(c) Rubber and metal's length

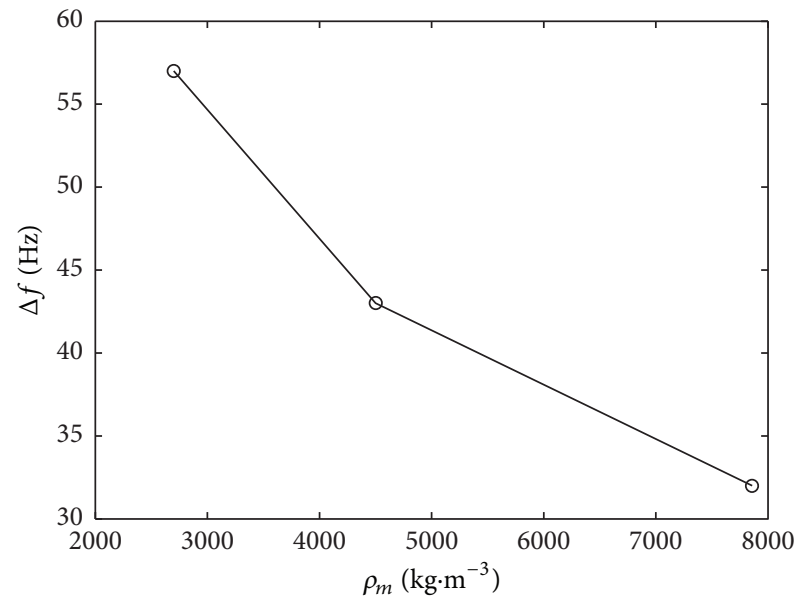

(b) Metal's density

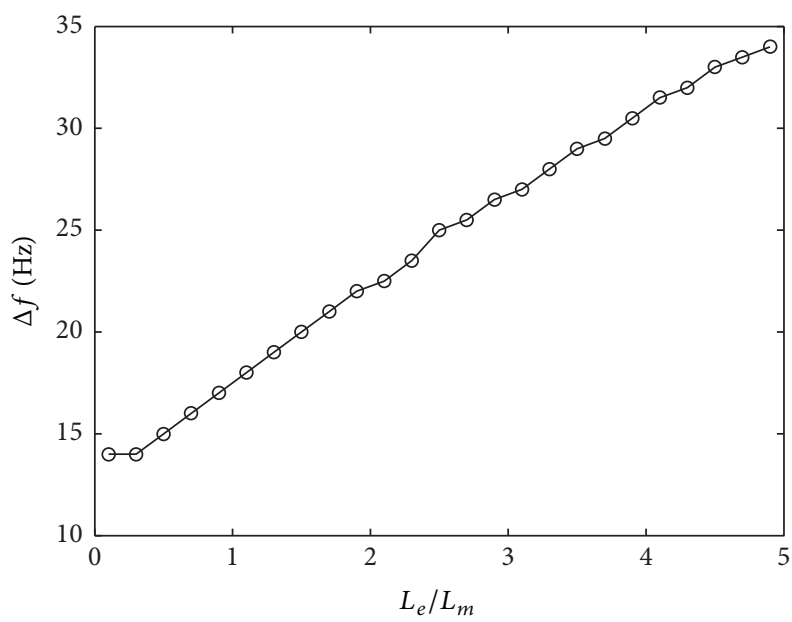

(d) Rubber/metal's length ratio

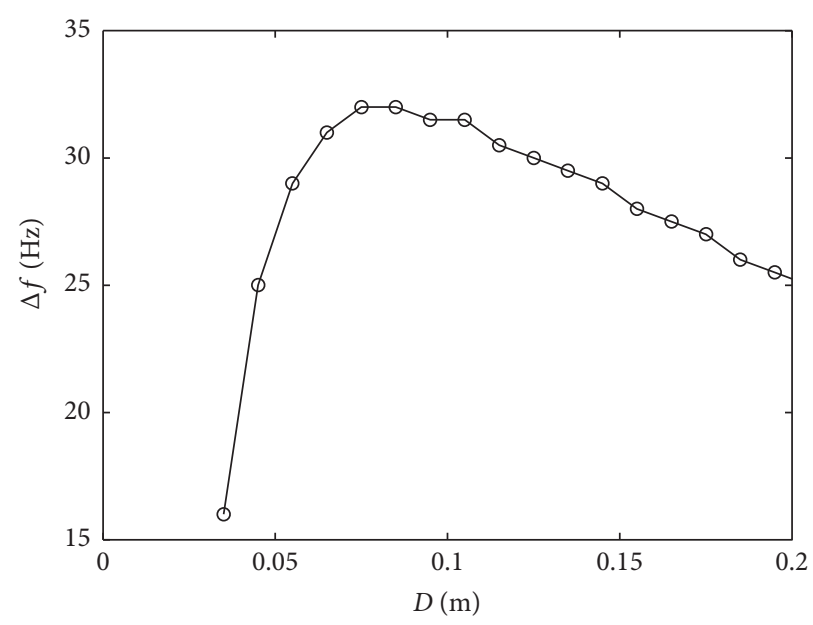

(e) Inner cylinder's diameter

Figure 3: Curves of influence of the boundary conditions on the vibration transmissibility. 
TABLE 2: Main geometric dimension.

\begin{tabular}{lcccc}
\hline Structure & Material & $\begin{array}{c}\text { Length } \\
(\mathrm{mm})\end{array}$ & External diameter $(\mathrm{mm})$ & Inner diameter $(\mathrm{mm})$ \\
\hline \multirow{2}{*}{ Upper cylinder } & Rubber & 30 & 70 & 35 \\
& Metal & 22 & 70 & 35 \\
Lower cylinder & Rubber & 30 & 70 & $/$ \\
& Metal & 22 & 70 & $/$ \\
\hline
\end{tabular}

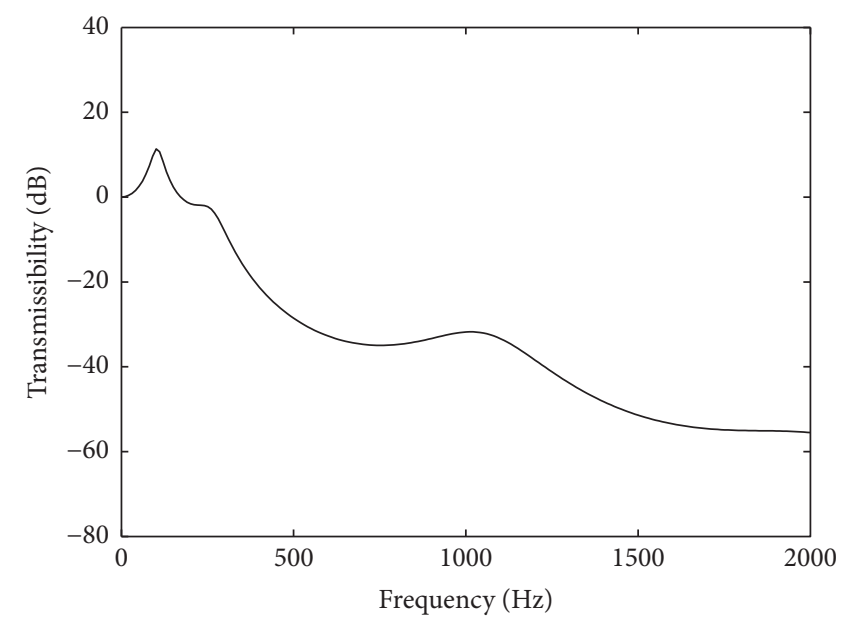

FIGURE 4: Transmissibility of the compounded periodic strut for the gearbox.

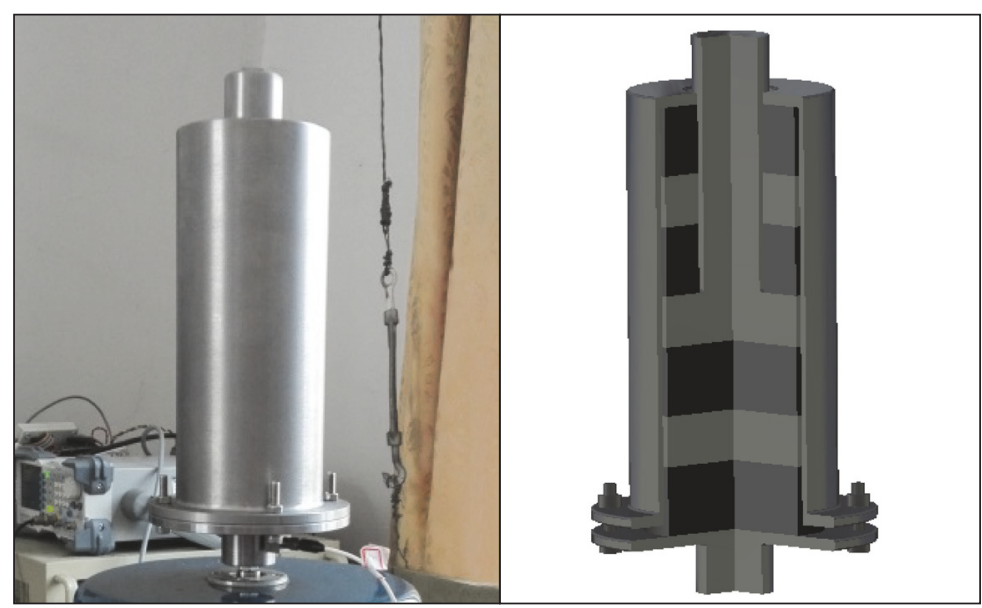

FIGURE 5: Image and cutaway view of a sample periodic strut.

fabrication of the sample strut will be performed in the next step.

4.5. Fabrication. Figure 5 shows an image and a cutaway view of the sample strut, illustrating the structure connection relationship and the locations of the components of the assembly. Some improvements have been implemented to allow for easy installation; for example, four bolt connections are added in the outer cylinder to apply the precompression of rubber. Because the bolt connection stiffness is much greater than the rubber stiffness, it can be approximated as a rigid connection.

\section{Experimental Study}

5.1. Overview. To demonstrate the broadband vibration attenuation characteristics of the strut presented in Section 4, shaker broadband excitation experimental investigations of 


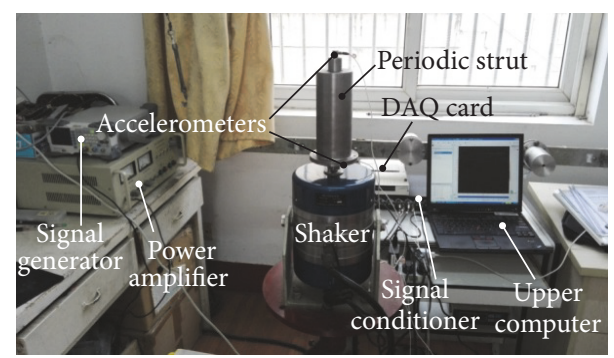

FIGURE 6: Experimental setup of shaker excitation.

a strut were conducted. This strut is then adjusted by the bolt connections to evaluate the effect of precompression. In addition, a gearbox excitation experiment is presented in this section to further demonstrate the feasibility of the use of the compounded periodic strut to suppress transfer of the gearbox vibration to the fuselage.

\subsection{Shaker Excitation}

5.2.1. Experimental Facilities. Figure 6 shows the experimental setup of the sample strut considered in this study. The vibration transfer characteristic of such a strut is obtained under the shaker excitation, a type of broad white noise signal in the range of $0-2000 \mathrm{~Hz}$ generated by a DG1032Z signal generator. Two PCB accelerometers are used here to collect vibration signals on both ends of the strut.

5.2.2. Experimental Results. To easily observe the vibration attenuation characteristics of the strut, the transmissibility is defined as the transmitted acceleration amplitude $a_{o}$, divided by the input amplitude $a_{i}$, and can be written as

$$
T=\frac{a_{o}}{a_{i}}
$$

Figure 7(a) illustrates the frequency responses in the range between 300 and $2000 \mathrm{~Hz}$ on both ends of the strut. The figure reveals that the vibration amplitude of the strut reduces at approximately $350 \mathrm{~Hz}$, and the attenuation amplitude increases with the frequency increasing. The acceleration is approximately zero when the frequency exceeds $1000 \mathrm{~Hz}$. Figure 7(b) shows the transmissibility curve of the strut; the curve verifies the broadband vibration attenuation characteristics of the compounded periodic strut, with the maximum reduction exceeding $60 \mathrm{~dB}$.

The experimental and analytical transmissibilities are compared for the sample strut. The experimental results show that the beginning frequency is $50 \mathrm{~Hz}$ higher than the analytical results because of the influence of rubber precompression, the installation errors of accelerometers, and so forth.

5.3. Precompression Testing. The influence of precompression on the transmissibility is investigated. In Figure 8, the experimental transmissibilities of the sample strut are plotted under
1-5 mm rubber compression deformations. The figure shows that the transmissibility curves have approximately the same magnitude under different levels of rubber prestrain, including the beginning frequency and the attenuation amplitude. As the curves suggest, the transmission characteristics of the compounded periodic strut appear to have little dependence on minor precompression deformation in the frequency range of $300-2000 \mathrm{~Hz}$.

\subsection{Gearbox Excitation}

5.4.1. Experimental Facilities. Normally, helicopter gear mesh vibration is transmitted into the gearbox housing through the shaft and bearing and then through the support struts into the fuselage, where the structure-borne sound is finally radiated into the cabin. Figure 9 shows the test facilities of the gearbox system used to simulate the transmission path of helicopter gear mesh vibration. The gearbox is driven by a motor, and the gearbox support system is constructed with the plain or sample periodic struts.

The test setup shown in Figure 9 is used to measure the transmission characteristics of the struts from the gearbox to the fuselage. Figure 10 displays the installation location of two LC0111 three-axis accelerometers. When the rotational speed of the motor is $900 \mathrm{rpm}$, the vibration response on both ends of the strut can be obtained.

5.4.2. Gearbox Vibration. This section gives the test results of the gearbox vibration used to determine whether the frequency distribution meets the requirement of the experimental conditions.

The numbers of teeth of the two gear pairs in the gearbox are $60 / 80$ and $32 / 40$. The corresponding gear mesh harmonic frequencies are $360 \mathrm{~Hz}, 720 \mathrm{~Hz}, 900 \mathrm{~Hz}, 1080 \mathrm{~Hz}, 1440 \mathrm{~Hz}$, and $1800 \mathrm{~Hz}$ at $900 \mathrm{rpm}$, where $360 \mathrm{~Hz}$ and $900 \mathrm{~Hz}$ are two basic gear tooth passage frequencies.

Figure 11 shows the frequency responses on the attachment points nearby the gearbox in the range between 0 and $2000 \mathrm{~Hz}$. The figure shows that both plain and periodic struts have obvious gear mesh harmonic tones, along with other frequency components of $450 \mathrm{~Hz}, 540 \mathrm{~Hz}$, and $1350 \mathrm{~Hz}$, which are caused by the wear of gears and so forth. In conclusion, the vibration spectrum of the experimental gearbox can be used to simulate the realistic helicopter gearbox excitation conditions.

5.4.3. Transmission Characteristics. Figure 12 shows the experimental transmissibilities of both plain and periodic struts under gear mesh excitation in the frequency range of $300-2000 \mathrm{~Hz}$. As the curves suggest, the transmission magnitude of the compounded periodic strut is much less than that of the plain strut, where the maximum reduction can exceed $40 \mathrm{~dB}$, which demonstrates its excellent broadband vibration attenuation characteristic. 


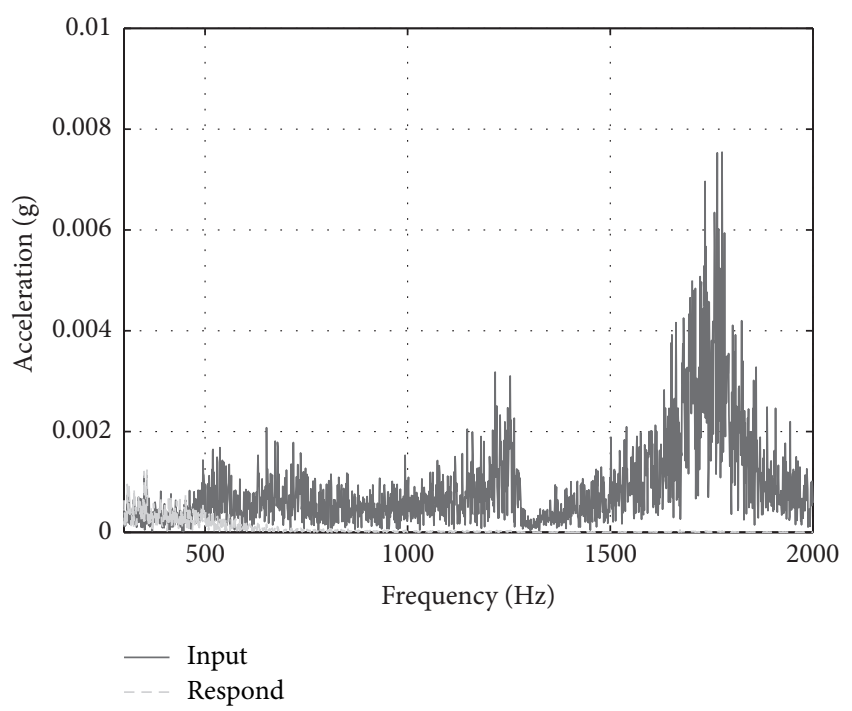

(a) Frequency response

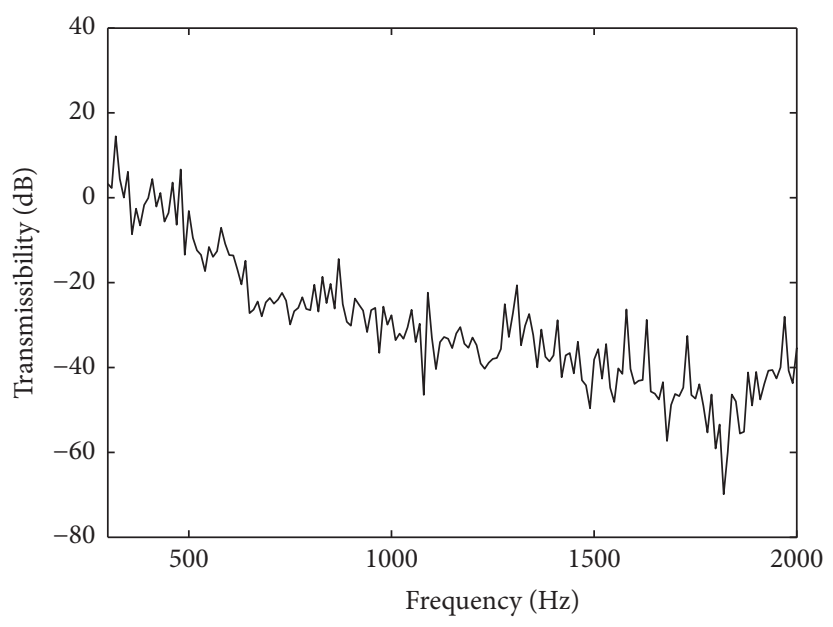

(b) Transmissibility curve

FIgURE 7: Results of the shaker excitation experiment.

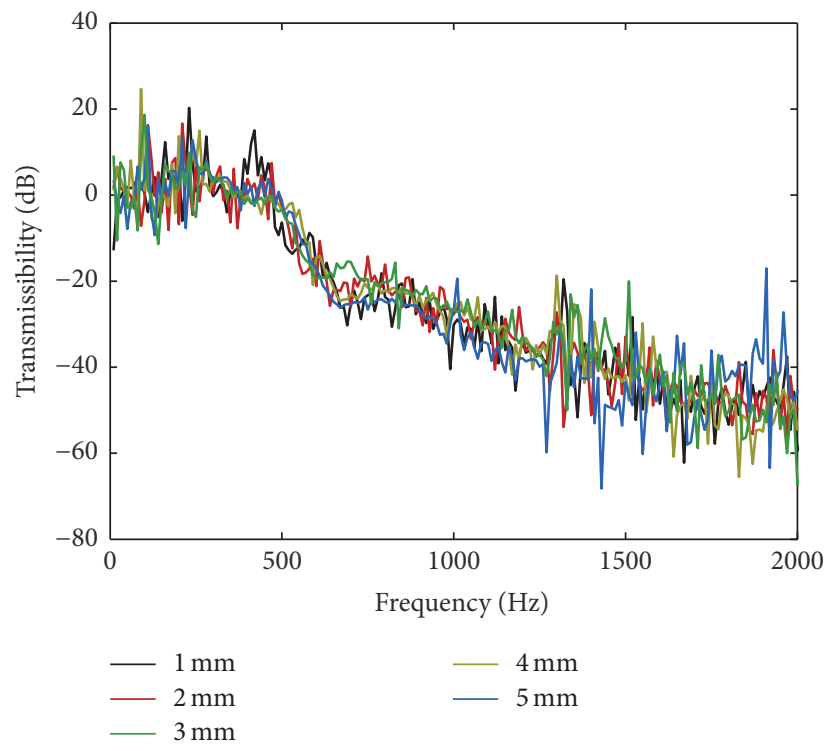

Figure 8: Acceleration transmissibility for different compression deformations.

\section{Conclusion}

This paper presented the feasibility verification process of the compounded periodic strut used to restrict vibration from the gearbox to the fuselage.

The effects of damping and boundary conditions were obtained based on simulation analysis. Damping can effectively inhibit the response amplitudes at the resonant frequencies of the compounded periodic strut and broaden the stop band range of the strut. The boundary conditions have an important influence on the stop band, especially on the beginning frequency for a finite periodic strut; thus it should not be ignored in the design of the strut. However, the influence is weakened when the periodic strut tends towards an infinite periodic structure.

The results from shaker excitation experimental investigations suggest that the compounded periodic strut has broadband vibration attenuation characteristics, and the maximum reduction exceeds $60 \mathrm{~dB}$. The stop bands of the compounded periodic strut appear to have little dependence on precompression in the frequency range of 300-2000 Hz.

The results from the gearbox excitation experimental investigations suggest that the compounded periodic strut can effectively restrict the vibration transmission from the gearbox to the fuselage. The vibration attenuations in excess of $40 \mathrm{~dB}$ are measured compared with the plain strut in the 


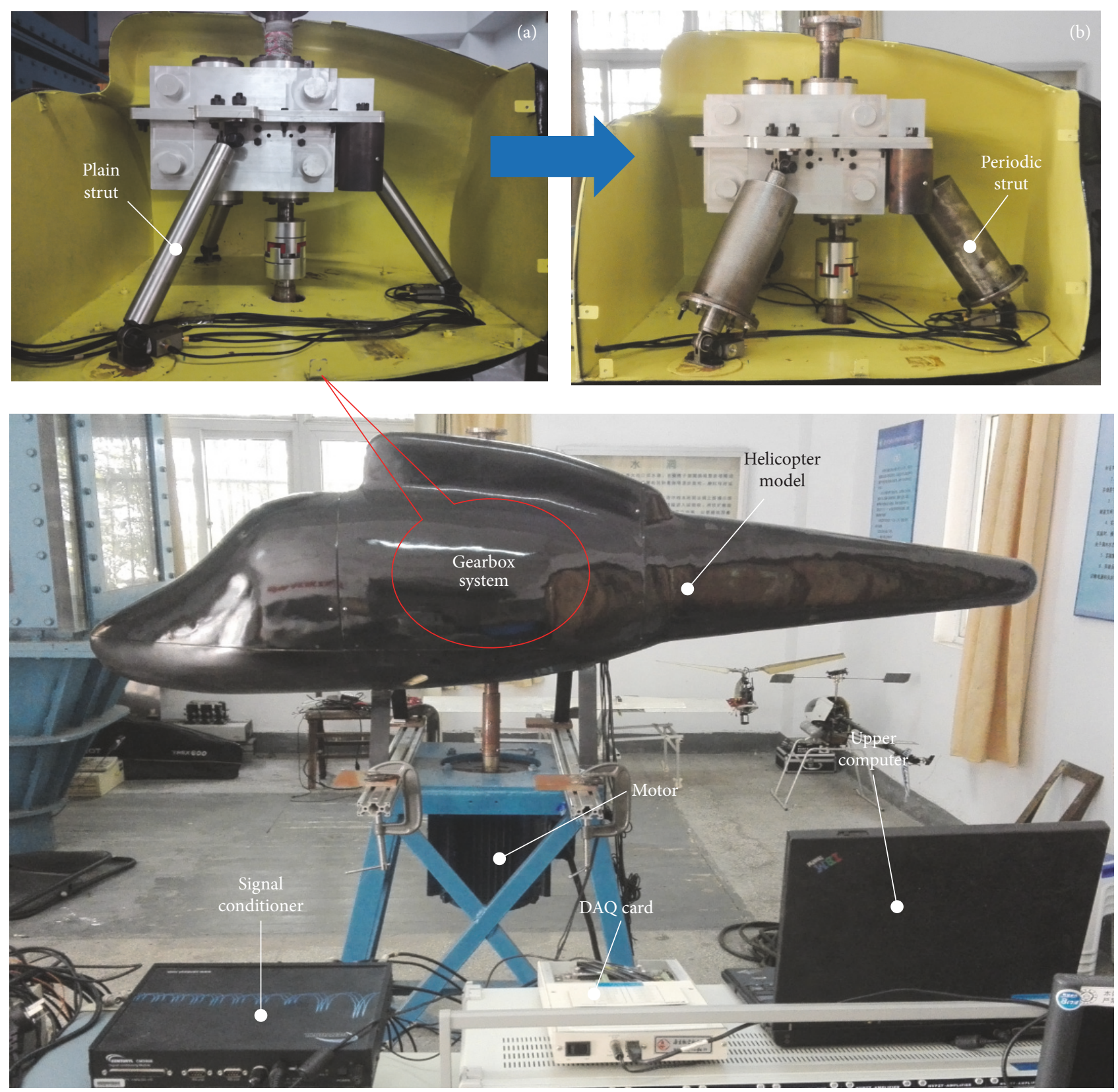

FIGURE 9: Experimental setup of gearbox excitation.

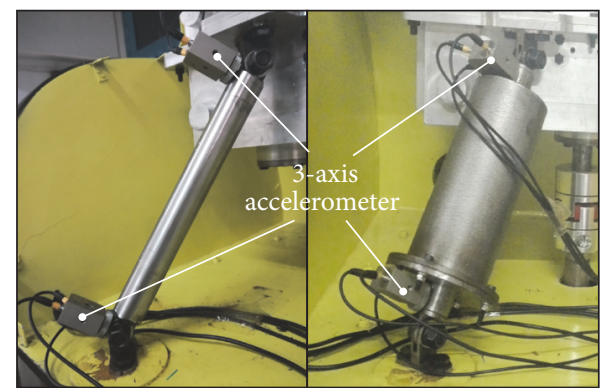

FIgURE 10: Installation locations of the accelerometers. frequency range from 300 to $2000 \mathrm{~Hz}$, verifying the feasibility of the strut used on the helicopter.

\section{Nomenclature}

A: Cross-sectional area, $\mathrm{m}^{2}$

$a_{o}$ : Output acceleration amplitude, $\mathrm{m} / \mathrm{s}^{2}$

$a_{i}$ : Input acceleration amplitude, $\mathrm{m} / \mathrm{s}^{2}$

$D$ : Inner cylinder's diameter, $\mathrm{m}$

E: Elastic modulus, $\mathrm{Pa}$

$E^{\prime}$ : Storage modulus, $\mathrm{Pa}$ 


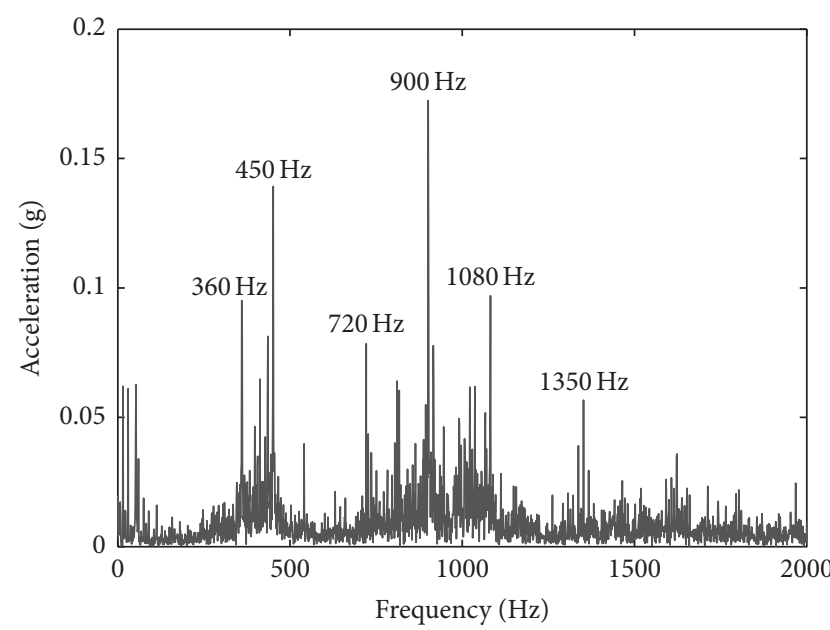

(a) Plain strut

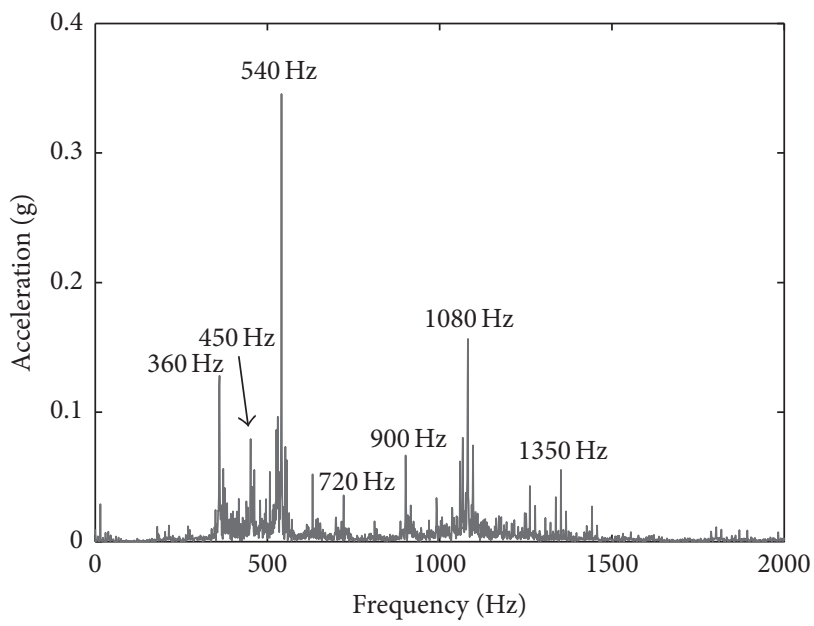

(b) Periodic strut

FIGURE 11: Frequency response on the gearbox attachment points.

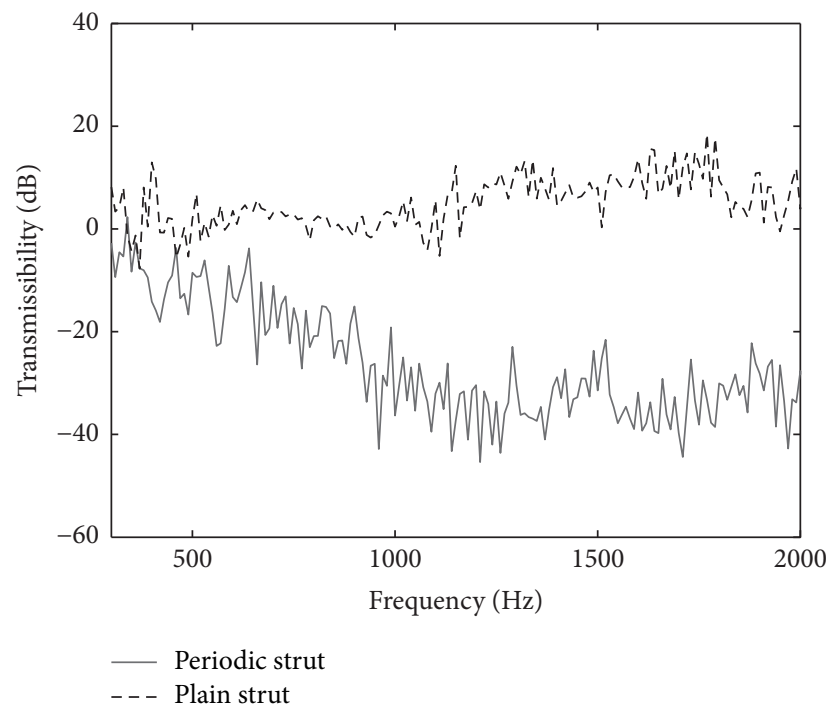

FIgURE 12: Experimental transmissibility of gearbox excitation.

$E^{\prime \prime}$ : $\quad$ Loss modulus, $\mathrm{Pa}$

$E_{e}: \quad$ Rubber's elastic modulus, $\mathrm{Pa}$

$F_{\mathrm{U}}$ : Longitudinal force of upper cylinder, $\mathrm{N}$

$F_{\mathrm{L}}$ : Longitudinal force of lower cylinder, $\mathrm{N}$

$F_{0}: \quad$ Amplitude of excited force, $\mathrm{N}$

$i$ : $\quad$ Imaginary unit

$k$ : $\quad$ Longitudinal wavenumber

$\mathbf{K}_{\text {sub }}$ : Dynamic stiffness matrix of a subcell

$\mathbf{K}_{p}$ : $\quad$ Dynamics stiffness matrix of $n$ subcells in parallel

$\mathbf{K}_{s}, \overline{\mathbf{K}}_{s}$ : Dynamics stiffness matrix of $n$ subcells in series

$\mathbf{K}_{d}$ : Damped dynamics matrix of the entire periodic strut

$L_{e}: \quad$ Length of rubber, $\mathrm{m}$
$L_{m}: \quad$ Length of metal, $\mathrm{m}$

$l$ : $\quad$ Longitudinal length of the subcell, $m$

$M$ : Periodic number of lower cylinder

$N$ : Periodic number of upper cylinder

$\rho_{m}:$ Density of metal, $\mathrm{kg} / \mathrm{m}^{3}$

$\rho: \quad$ Mass density, $\mathrm{kg} / \mathrm{m}^{3}$

$\mathbf{T}_{s}$ : Transfer matrix of $n$ subcells in series

$\mathbf{T}_{\text {sub }}$ : Transfer matrix of a subcell

T: Transmissibility

$T_{Z Z}$ : Transmissibility in free-free conditions

$T_{Z G}$ : Transmissibility in free-fix conditions

$T_{Z B}$ : Transmissibility in free-base conditions

$u_{U}$ : Longitudinal displacement of upper cylinder, $m$

$u_{\mathrm{L}}$ : Longitudinal displacement of lower cylinder, $m$

$u_{0}$ : Amplitude of the excited displacement, $\mathrm{m}$

$\omega$ : Vibration frequency, $\mathrm{rad} / \mathrm{s}$

$X: \quad$ Lateral axis $X$

$Y: \quad$ Lateral axis $Y$

$Z$ : $\quad$ Longitudinal axis.

\section{Subscripts}

e: Rubber

$m$ : Metal

$n$ : Number of subcells

$\mathrm{U}$ : Upper cylinder

L: Lower cylinder

$s$ : Series

p: Parallel.

\section{Conflicts of Interest}

The authors declare that they have no conflicts of interest. 


\section{Acknowledgments}

The authors would like to acknowledge the National Key Laboratory Foundation (no. 61422200402162220003) and National Natural Science Foundation of China (no. 51375229).

\section{References}

[1] M. J. Brennan, R. J. Pinnington, and S. J. Elliot, "Mechanisms of noise transmission through helicopter gearbox support struts," Journal of Vibration and Acoustics, Transactions of the ASME, vol. 116, no. 4, pp. 548-554, 1994.

[2] J. T. Szefi, Helicopter gearbox isolation using periodically layered fluidic isolators [Ph.D. thesis], Mechanical and Nuclear Engineering Dept., Pennsylvania State Univ., University Park, Pennsylvania, PA, USA, 2003.

[3] T. A. Millott, W. A. Welsh, C. A. Yoerkie Jr., D. G. MacMartin, and M. W. Davis, "Flight test of active gear-mesh noise control on the S-76 aircraft," in Proceedings of the 1998 54th Annual Forum, pp. 241-249, Washington, DC, May 1998.

[4] J. S. Pollard, "Helicopter gear noise and its transmission to the cabin, 3rd European Rotorcraft and Powered Lift Aircraft Forum," Sep, pp. 52.1-52.10, 1977.

[5] C. A. Yoerkie, J. A. Moore, and J. E. Manning, Development of rotorcraft interior. Noise control concepts. Phase 1: Definition study, NASA CR-166101, 1983.

[6] T. J. Sutton, S. J. Elliott, M. J. Brennan, K. H. Heron, and D. A. C. Jessop, "Active isolation of multiple structural waves on a helicopter gearbox support strut," Journal of Sound and Vibration, vol. 205, no. 1, pp. 81-101, 1997.

[7] R. Maier, F. Hoffmann, S. Tewes, and M. Bebesel, "Active vibration isolation system for helicopter interior noise reduction," in Proceedings of the 8th AIAA/CEAS Aeroacoustics Conference and Exhibit, 2002, pp. 2002-2495, June 2002.

[8] F. Hoffmann, R. Maier, P. Janker, F. Hermle, and A. Berthe, "Helicopter interior noise reduction by using active gearbox struts," in Proceedings of the 12th AIAA/CEAS Aeroacoustics Conference, pp. 2006-2604, May 2006.

[9] G. P. Mathur, J. M. O'Connell, R. JanakiRam, and C. R. Fuller, "Analytical and experimental evaluation of active structural acoustic control (ASAC) of helicopter cabin noise," in Proceedings of the 40th AIAA Aerospace Sciences Meeting and Exhibit, AIAA Paper, pp. 2002-1035, January 2002.

[10] Y. Lu and X. Ma, "Active control of multifrequency helicopter vibrations using discrete model predictive sliding mode control," Proceedings of the Institution of Mechanical Engineers, Part G: Journal of Aerospace Engineering, vol. 230, no. 4, pp. 668-680, 2016.

[11] G. Zhao, N. Alujevic, B. Depraetere, G. Pinte, J. Swevers, and P. Sas, "Active structural acoustic control of rotating machinery using piezo-based rotating inertial actuators," in Proceedings of the 26th International Conference on Noise and Vibration Engineering, ISMA, Leuven, pp. 225-239, Belgium, German, September 2014.

[12] K. Gulyas, G. Pinte, F. Augusztinovicz, W. Desmet, and P. Sas, "Active noise control in agricultural machines," in Proceedings of the 2002 International Conference on Noise and Vibration Engineering, ISMA, Leuven, pp. 11-21, Belgium, German, September 2002.
[13] S. Asiri, A. Baz, and D. Pines, "Periodic struts for gearbox support system," JVC/Journal of Vibration and Control, vol. 11, no. 6, pp. 709-721, 2005.

[14] J. T. Szefi, E. C. Smith, and G. A. Lesieutre, "Analysis and design of high frequency periodically layered isolators in compression," in Proceedings of the 41st AIAA/ASME/AHS/ASC Structures, Structural Dynamics, and Materials Conference and Exhibit, AIAA Paper, pp. 2000-1373, April 2000.

[15] J. Szefi, E. Smith, and G. Lesieutre, "Formulation and validation of a Ritz-based analytical model for design of periodicallylayered isolators in compression," in Proceedings of the 42nd AIAA/ASME/AHS/ASC Structures, Structural Dynamics, and Materials Conference and Exhibit, AIAA Paper, pp. 2001-1684, April 2001.

[16] J. T. Szefi, E. C. Smith, and G. A. Lesieutre, "Design and analysis of high-frequency periodically layered isolators for helicopter gearbox isolation," in Proceedings of the 44th AIAA/ASME/ASCE/AHS/ASC Structures, Structural Dynamics, and Materials Conference, AIAA Paper, pp. 2003-1784, April 2003.

[17] J. T. Szefi, E. C. Smith, and G. A. Lesieutre, "Design and testing of a compact layered isolator for high-frequency helicopter gearbox isolation," in Proceedings of the 45th AIAA/ASME/ ASCE/AHS/ASC Structures, Structural Dynamics, and Materials Conference, AIAA Paper, pp. 2004-1947, April 2004.

[18] F. J. Wang and Y. Lu, "Research on gearbox periodic strut for helicopter cabin noise reduction," Hangkong Xuebao/Acta Aeronautica et Astronautica Sinica, vol. 37, no. 11, pp. 3370-3384, 2016.

[19] I. Guelho, L. Reis, and M. Fontul, "Complex Young Modulus for Rubbercork Composites," in Proceedings of the 15th International Conference on Experimental Mechanics, FEUP, Porto, Portugal, July 2012. 


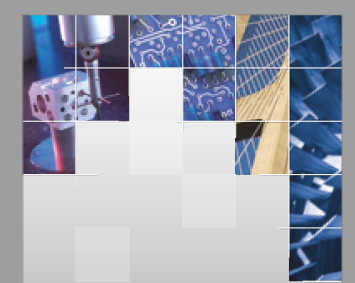

\section{Enfincering}
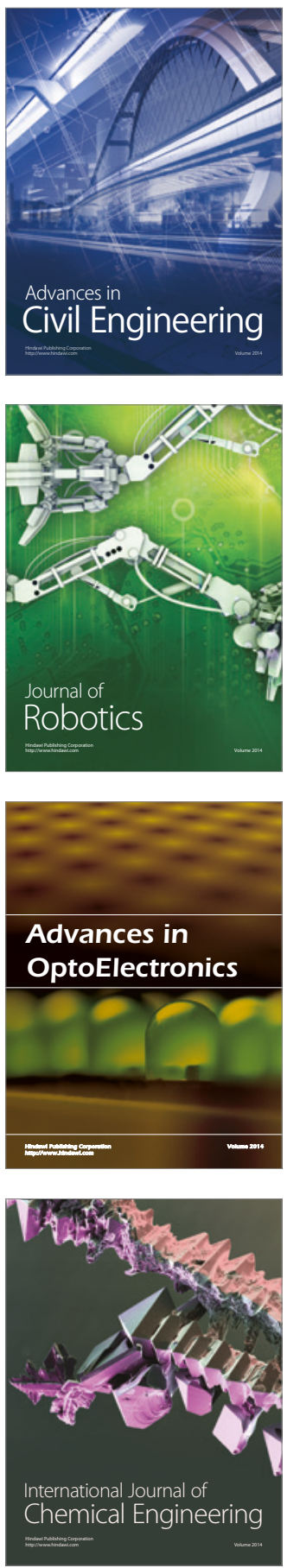

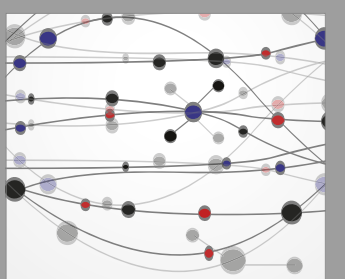

The Scientific World Journal

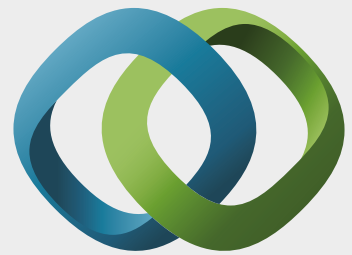

\section{Hindawi}

Submit your manuscripts at

https://www.hindawi.com
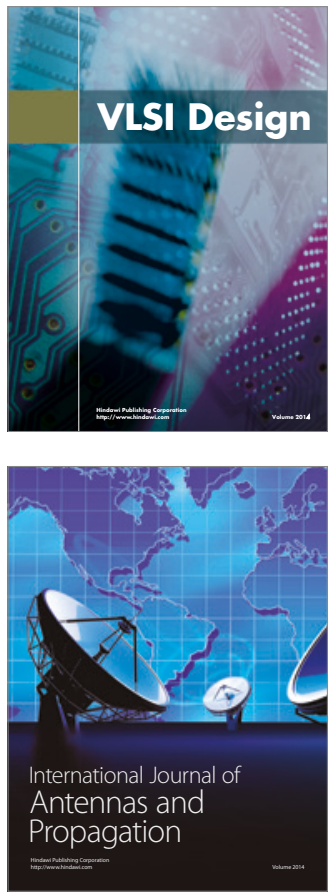

\section{Rotating}

Machinery
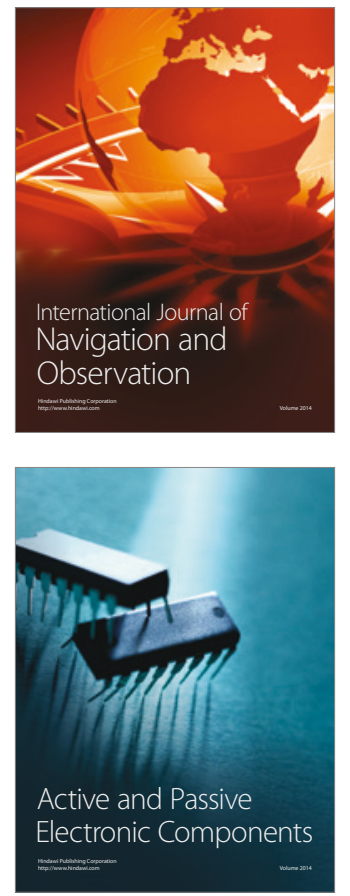
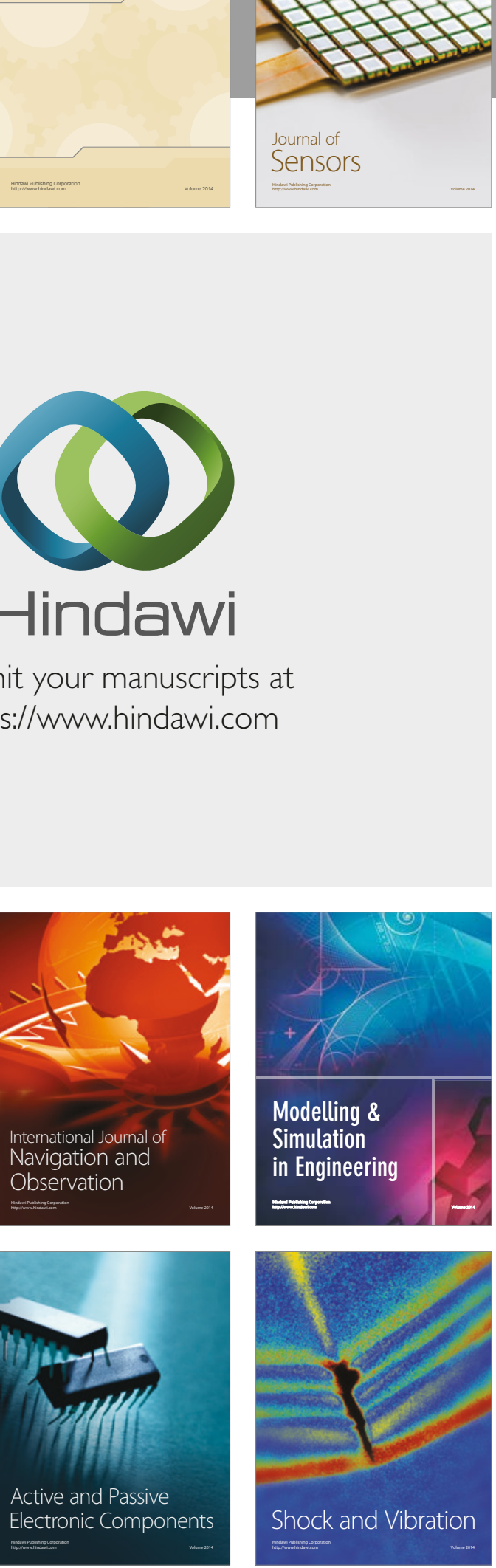
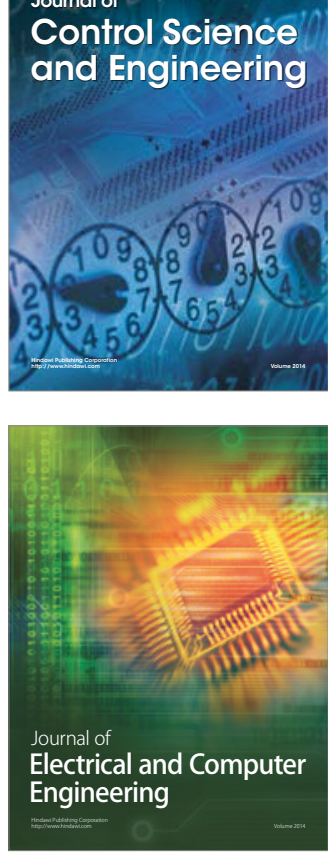

Distributed

Journal of

Control Science

and Engineering
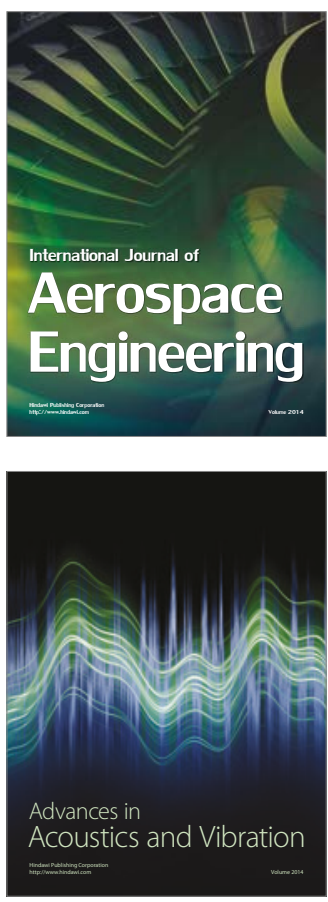

Sensor Networks 